\title{
De Panamá a Magallanes: pasajes-mundo y secretos de la tierra desde la figura de Juan Ladrillero
}

Resumen: Este artículo analiza la trayectoria del piloto Juan Ladrillero [1490-1559] en expediciones hispánicas de expansión en América con el fin de probar la reciprocidad entre prácticas cosmográficas y estrategias geopolíticas en dos pasajes-mundo que conectaron a América con el resto del planeta: el istmo de Panamá y el estrecho de Magallanes. En este marco, se destaca la función del lenguaje del "secreto de la tierra" como dispositivo de comprensión política y geográfica, altamente útil al interior de los procesos de construcción territorial americana y, con ello, de proyección global de la monarquía hispana en la primera mitad del siglo XVI.

Palabras clave: pasaje mundo, secreto, pilotos, cosmografía, geopolítica de las Américas, historia del conocimiento moderno.

\section{From Panamá to Magallanes: world-passages and the secrets of the land from the perspective of pilot Juan Ladrillero}

Abstract: This article analyzes the role of pilot Juan Ladrillero [1490-1559] in expeditions of Hispanic expansion in America, as a key to understand the relationship between cosmographic knowledge and geopolitical strategies in two world-passages that connected the New World with the rest of the globe: the Isthmus of Panama and the Strait of Magellan. In this context, the language of the "secrets of the land" is highlighted as a useful device for political and geographical understanding of the processes of territorial construction and expansion in the New World, and with it, the global projection of the Hispanic monarchy in the first half of the 16th century.

Keywords: world passage, secret, pilots, cosmography, geopolitics of the Americas, early modern history of knowledge.

\section{De Panamá a Magalhães: passagens-mundo e segredos da terra do ponto de vista da figura de Juan Ladrillero}

Resumo: Este artigo analisa a trajetória do piloto Juan Ladrillero [1490-1559] em expedições de expansão hispânica na América, a fim de provar a reciprocidade entre práticas cosmográficas e estratégias geopolíticas em duas passagensmundo que conectaram a América com o resto do planeta: o Istmo do Panamá e o Estreito de Magalhães. Nesse contexto, analisa-se a função da linguagem do "segredo da terra" como dispositivo de compreensão política e geográfica, muito útilnos processos de construção territorial americana e, por essa via, de projeção global da monarquia hispânica na primeira metade do século XVI.

Palavras-chave: passagem-mundo, segredo, pilotos, cosmografia, geopolítica das Américas, história do conhecimento moderno.

Cómo citar este artículo: Mauricio Onetto Pavez y Andrés Vélez Posada, "De Panamá a Magallanes: pasajes-mundo y secretos de la tierra desde la figura de Juan Ladrillero", Trashumante. Revista Americana de Historia Socia/16 [2020]: 34-57.

DOI: 10.17533/udea.trahs.n16a03

Fecha de recepción: 8 de junio de 2019

Fecha de aprobación: 5 de marzo 2020

Mauricio Onetto Pavez: Doctor en Historia y Civilizaciones por la École des Hautes Études en Sciences Sociales. Docente-Investigador de la Universidad Autónoma de Chile.

Correo electrónico: mauricio.onetto@uautonoma.cl

Andrés Vélez Posada: Doctor en Historia y Civilizaciones por la École des Hautes Études en Sciences Sociales. Profesor e investigador de la Universidad EAFIT.

Correo electrónico: avelezp6@eafit.edu.co 


\title{
De Panamá a Magallanes: pasajes-mundo y secretos de la tierra desde la figura de Juan Ladrillero ${ }^{\star}$
}

\author{
Mauricio Onetto Pavez y Andrés Vélez Posada
}

\section{Pasajes-mundo: espacios de construcción territorial}

El 22 de mayo de 1581, el presidente de la Real Audiencia de Panamá, Juan LLópez de Cepeda, envió una carta al rey Felipe II donde le relataba algunos inconvenientes frente a la seguridad de aquel lugar considerado como una de las puertas de América. El escrito mostraba la inquietud que se vivía después de que Francis Drake transitara por el Estrecho al extremo sur del continente y se aliara, cerca de Panamá, con comunidades de negros cimarrones que se encontraban en rebelión. Es así como, según Cepeda, "las dos puertas que tiene esta Mar del Sur para su entrada ambas han sido acometidas por los Inglesses".

Para justificar su petición de ayuda para defensa, el licenciado Cepeda realizó una lectura geopolítica del continente. ${ }^{2}$ Para él, la solución residía en proteger Panamá y en controlar definitivamente el estrecho de Magallanes, lugar que para esa fecha aún no tenía asentamiento español y del cual se conocían pocas referencias. Por este último motivo, Cepeda señalaba que poseía una "relación" sobre dicho estrecho que podía revertir el desconocimiento. Se trataba de un escrito sobre cómo navegarlo, elaborado por el capitán y piloto Juan Ladrillero en 1559:

* Este artículo es parte de los siguientes proyectos de investigación: CONICYT-Chile Red GEOPAM, $n^{\circ}$ REDI170261; FONDECYT n ${ }^{\circ}$ 11150474; Universidad Autónoma de Chile DIUA 152-2019 en los que participa el doctor Mauricio Onetto Pavez. Así como:"Genius before Romanticism: Ingenuity in Early Modern Art and Science", University of Cambridge / CRASSH, proyecto patrocinado por el European Reasearch Council; "Ingenio Indiano: ambientes del conocimiento en el trópico americano" proyecto con código 952-000023, Universidad EAFIT, Colombia, en los que participa el doctor Andrés Vélez Posada.

1. "Carta del licenciado Cepeda al rey", Panamá, 22 de mayo de 1581. AGI, Sevilla, Panamá, 13, r. 20 , n. 127, f. 1. En las citas hemos modernizado la ortografia.

2. Entendemos geopolítica como una práctica estratégica del espacio en la que se movilizan motivaciones y decisiones humanas a través de representaciones y disposiciones geográficas. Bertha Koiffmann Becker, “A Geografia e o Resgate da Geopolítica”, Espaço Aberto 2.1 (2012): 118. 
De la otra puerta estrecho de Magallanes que se ha entrado el corsario Francisco, su descripción envío por escrito al Consejo de vuestra majestad en el armada antes desta hecha por un capitán y piloto diestro llamado Ladrillero a quien el Marqués de Cañete envió del Perú para explorar aquel paso aunque en ella no hace mención de la angostura y fondo que tiene en las ciento y cincuenta leguas que afirma que son de mar a mar, en todo lo demás me parece se declara bien. ${ }^{3}$

Aunque esta pieza ya circulaba por las audiencias y virreinatos americanos, Cepeda deseaba ponerla nuevamente en conocimiento del Consejo de Indias para que la monarquía se decidiera a fortificar el paso y responder a la afrenta inglesa. ${ }^{4}$

Para completar su lectura geopolítica el licenciado Cepeda también enviaba dos "estampas" cartográficas hechas por él mismo, una alusiva a los problemas de la insurrección de cimarrones en el istmo y otra con una visión hemisférica desde la tórrida Panamá hasta el antártico cabo Deseado y su proyección hacia el mar del Sur:

y así envío ahora su duplicado al presidente y Consejo de vuestra majestad con dos estampas descripciones, una particular de la tierra en que estos negros alzados andan, la otra es más entera que contiene casi todo este nuevo orbe en que se verá los estrechos deste reino y Magallanes y cómo ambos abrazan en medio de sí continuado la costa a esta mar del Sur apetecida y envidiada de todo el mundo. ${ }^{5}$

El informe de Cepeda revela cómo los sitios del Estrecho y Panamá eran pasajes-mundo, es decir, espacios geográficos que vinculaban simultáneamente problemáticas locales con dimensiones hemisféricas y globales. Asimismo, muestra cómo el proceso de construcción político-territorial americana es inseparable de actos de conocimiento de individuos como Juan Ladrillero. ${ }^{6}$ En este sentido, Ladrillero

3. "Carta del licenciado Cepeda" f. 2. José de Acosta afirma haber leído en el Perú la "relación notable" de Ladrillero donde se declaraba cómo "le halló y pasó [...] Aunque dice no haberse atrevido a desembocar el Estrecho sino que, habiendo ya reconocido la mar del Norte, dio la vuelta por el aspereza del tiempo: que era ya entrado el invierno y venían, según dice, las olas del Norte furiosas, y las mares hechas todas espuma de bravas". Josef de Acosta, Historia Natural y Moral de las Indias (Madrid: Consejo Superior de Investigaciones Científicas, 2008) 72. Para un análisis contextual de esta relación, véase Julián González-Barrera, "La derrota a través del Estrecho de Magallanes: el viaje olvidado de Juan Ladrillero (1557-1559)”, Atenea 501 (2010): 11-33.

4. Dice Cepeda: "reconocer aquel Estrecho y entrada y, no se pudiendo cegar, se fortifique y defense en lugar conveniente como vuestra merced lo habrá mandado remediar". "Carta del licenciado Cepeda" f. 3. La idea ya se discutía en la península ibérica, pues a finales de ese mismo año saldría la expedición de Diego Flores codirigida por Sarmiento de Gamboa, quien iría a tomar potestad sobre el estrecho de Magallanes. Véase Nuria González Alonso, "Diego Flores de Valdés y la expedición al estrecho de Magallanes en el año 1581", Anales del Museo de América 22 (2014): 152-161; Joaquín Zuleta Carrandi, "La fortificación del estrecho de Magallanes: un proyecto al servicio de la imagen de la monarquía", Revista Complutense de Historia de América 39 (2013): 153-176.

5. "Carta del licenciado Cepeda" f. 2. Estas "estampas descripciones" que refiere la carta no han sido identificadas.

6. Sobre la reciprocidad e imbricación de la ciencia y la política en el contexto hispánico, véase Arndt Brendecke, Imperio e información. Funciones del saber en el dominio colonial español (Madrid / Frankfurt: Iberoamericana / Vervuert, 2016) 158. 
es un actor ejemplar que muestra cómo los "descubrimientos" de los pasajesmundo de Balboa en 1513 y de Magallanes en 1520 eran procesos en constante sincronización y articulación. En este artículo pretendemos evidenciar precisamente cómo las labores cosmográficas de Ladrillero en las inmediaciones de estos pasajes-mundo, y particularmente en el estrecho de Magallanes, fueron bases efectivas y concretas para las empresas de proyección y expansión de la monarquía española desde América. Como se explicará, estas labores cosmográficas se inscribieron dentro de la motivación de conocer y poseer los secretos de la tierra, según la expresión recurrente de la primera mitad del siglo XVI.

Denominamos al estrecho de Magallanes y al istmo de Panamá como pasajesmundo en cuanto hitos y espacios no solo geográficos sino epistémicos que resignificaron la concepción del mundo moderno. Esta propuesta conceptual de pasaje-mundo aglomera significados y procesos ligados a las obsesiones, expectativas y búsquedas de pasajes geográficos interoceánicos durante el siglo XVI. El estrecho de Magallanes, en cuanto paso por antonomasia, permitió conectar y crear saberes a escala global. Su función como pasaje-mundo es evidente de múltiples formas en fuentes cartográficas y compendios cosmográficos en los cuales el Estrecho se muestra como un punto desde donde se puede observar el Globo y realizar la experiencia de la circunnavegación. Asimismo, se muestra como acceso a la austral Terra Australis Incognita, como línea de rumbo utilizada para especular sobre el negocio de la especería o, según se aprecia con el licenciado Cepeda, como puerta y brazo de seguridad continental.

Este concepto se inspira en la idea de conciencia-mundo que se inició con la aparición de América en la cultura geográfica europea en 1492 y que propició discusiones políticas y cosmológicas en torno a los límites de la ecúmene y del universo. ${ }^{7}$ Tras la noticia de la circunnavegación de Magallanes y Elcano, esta conciencia-mundo pudo encontrar una certeza material y epistemológica para proyectarse y ponerse en práctica a través de un pasaje. En otras palabras, la experiencia de la circunnavegación continua, posible gracias al paso por el estrecho de Magallanes, permitió ordenamientos y conexiones globales inéditas que aceleraron en las monarquías europeas el deseo de poseer, dominar y ocupar el globo. Dentro de esta nueva dinámica, los "pasajes", "estrechuras" y "lugares de paso" estuvieron en el centro político y cosmográfico, pues fomentaban la expansión, la conexión y la circulación a través de sitios en principio controlables.

\section{Juan Ladrillero y su itinerario americano}

La confluencia de prácticas cosmográficas y políticas en Juan Ladrillero lo hacen un agente clave para entender cómo las experiencias en estos pasajes-mundo, y puntualmente en el angosto paso del estrecho de Magallanes, le dieron a los territorios americanos y a los espacios de navegación del mar del Sur una dimensión

7. Louise Bénat-Tachot y otros, Les processus d'americanisation, vols. I y II (Paris: Le Manuscrit, 2012). 
hemisférica y global que España debía custodiar ante las pretensiones de las monarquías rivales.

Probablemente oriundo de Moguer y formado como piloto real en Sevilla, Juan Ladrillero estaría desde la década de 1520 en la Carrera de las Indias reuniendo experiencia en las artes de navegar. ${ }^{8}$ Como muchos de los pilotos de aquellas décadas, Ladrillero tuvo una formación basada en la fusión de dos tradiciones cosmográficas: la práctica y la matemática. ${ }^{9}$ Usó herramientas de los “prácticos”, cuya forma de operar se basaba en las observaciones y anotaciones intuitivas durante las navegaciones, y también de los "cosmógrafos", quienes se basaban en cálculos y registros metódicos. ${ }^{10}$ La confluencia en Ladrillero de ambas habilidades para la descripción de costas, ríos y valles, así como las medidas de latitud y cálculo de longitudes en América fueron destacadas y premiadas con misiones de alta importancia para la Corona.

Sus capacidades fueron reconocidas en diferentes lugares de América. Quienes lo conocieron se referían a él como un "hombre muy diestro y entendido en las cosas de la mar", ${ }^{11}$ y que junto con "Hernán Gallego y Diego Gallego, eran de los mejores pilotos que había en la tierra". ${ }^{12}$ La fama de Ladrillero fue resaltada por varios cronistas y autoridades. Pedro Cieza de León, quien se encontró varias veces con Ladrillero entre 1539 y 1550, le reconoció haber navegado y explorado el lago Titicaca. ${ }^{13}$ Gonzalo Fernández de Oviedo lo describió como "diligente hombre y que entendía buenas cosas de la tierra y de la mar", mientras que Juan

8. La biografía del itinerante Ladrillero está por fuera de los objetivos de este artículo.Valga apuntar que existen registros de un homónimo: Juan Fernández Ladrillero, piloto cercano a Pedro de Alvarado, activo en Nueva España y vecino de Colima.Véase González-Barrera 12-14.

9. Las tensiones entre prácticos y matemáticos de 1535 a 1560 confrontaron personajes de renombre como Sebastián Cabot, Diego Gutiérrez, Alonso de Santa Cruz y Pedro de Medina. Las desavenencias estuvieron centradas en los modos de construcción de cartas de navegar y en las formas de registrar la experiencia. Estos debates indican el momento en que la cosmografia se convertía en saber clave para la toma de decisiones políticas de la Corona. Véase Brendecke 183-226; María M. Portuondo, Ciencia secreta. La cosmografía española y el Nuevo Mundo (Madrid / Frankfurt: Iberoamericana / Vervuert, 2013) 68-100. Para un panorama de la Casa de Contratación en este siglo, véase Francisco Fernández López, "La Casa de la Contratación de Indias: gestión, expedición y control documental (siglos XVI-XVII)", Relaciones. Estudios de Historia y Sociedad 36.144 (2015): 169-193.

10. Antonio Sánchez Martínez, "Los artífices del Plus Ultra: pilotos, cartógrafos y cosmógrafos en la Casa de la Contratación de Sevilla durante el siglo XVI", Hispania. Revista Española de Historia 70.236 (2010): 628 .

11. Testimonio de Lorenzo Vaca da Silva en la probanza de los méritos y servicios de García de Mendoza y Manrique, mayo de 1561. José Toribio Medina, comp., Colección de documentos inéditos para la historia de Chile. Desde el viaje de Magallanes hasta la batalla de Maipo, 1518-1818, t. XXVII (Santiago: Imprenta Elzeviriana, 1901) 130.

12. Testimonio de Juan de Riva Martín en la probanza de los méritos y servicios de García de Mendoza y Manrique, mayo de 1561. Medina, Colección de documentos inéditos, t. XXVII, 67.

13. Pedro Cieza de León, Crónica del Perú. El señorío de los Incas (Caracas: Biblioteca Ayacucho, 2005) 84 y 261. 
de Castellanos lo llamaba "en cosas de la mar experto". ${ }^{14}$ Este piloto encarnaba la movilidad posible en la América española: de Sevilla a las islas del Caribe, de Panamá a las espesas selvas del Chocó, de las alturas del lago Titicaca a los laberínticos canales pelágicos del estrecho de Magallanes.

Activo en las campañas de conquista en el Nuevo Reino de Granada y luego en las guerras civiles y posterior reestructuración del virreinato del Perú, Juan Ladrillero tuvo injerencia en las misiones militares de autoridades como Juan de Vadillo, Pascual de Andagoya, Sebastián de Belalcázar, Blasco Núñez de Vela, Pedro La Gasca y Andrés Hurtado de Mendoza. Su itinerario se puede dividir en tres momentos. En el primero, entre 1537 y 1547, Ladrillero participó en la conquista y expansión de las gobernaciones de Popayán y San Juan — con el propósito de conocer "los secretos de la tierra" del territorio occidental del Nuevo Reino de Granada- En el segundo, entre 1548-1555, Ladrillero fue junto con el presidente La Gasca a enfrentar las rebeliones de los Pizarro y, luego, con las nuevas mercedes y beneficios, consiguió una encomienda en Chuquiago (La Paz), donde labró una mina cerca de Potosí. ${ }^{15} \mathrm{Al}$ tercer momento de su itinerario, del que más se habla en las fuentes hasta ahora encontradas, lo marcan el impulso económico del virreinato del Perú y el renovado interés geopolítico en el estrecho de Magallanes.Afines con las iniciativas de Pedro de Valdivia, las autoridades decidieron dirigir sus esfuerzos a extender efectivamente su dominio hasta los extremos australes de la gobernación de Chile con el fin de pacificar la tierra de Arauco y, una vez más, develar los secretos de la tierra vinculados con el estrecho de Magallanes. Juan Ladrillero fue llamado para reabrir y describir el paso en una trayectoria que no se había descrito: desde el mar del Sur hacia el mar del Norte. Antes de concentrarnos en este último episodio, es preciso profundizar en cómo Ladrillero puso sus habilidades de navegación y cosmografia al servicio de los deseos del Consejo de Indias de conocer los secretos de la tierra de los pasajes-mundo americanos.

\section{El secreto de las tierras americanas}

La especulación, las expectativas y la curiosidad de los agentes y autoridades monárquicas ante los territorios desconocidos de América hicieron del lenguaje del secreto un poderoso medio conceptual para organizar el conocimiento y dar sentido a las empresas de "descubrimiento" y "expansión” ibéricas. ${ }^{16}$ En su amplitud

14. Gonzalo Fernández de Oviedo, Historia general y natural de las Indias, tercera parte (Madrid: Imprenta de la Real Academia de la Historia, 1855) 128. Juan de Castellanos cuenta que Belalcázar envió con treinta hombres "al diestro capitán Juan Ladrillero / a descubrir dónde la mar batía / y ver la costa como marinero [...] por ser en cosas de la mar esperto". Juan de Castellanos, Elegías de varones ilustres de las Indias, t. 4 (Madrid: Imprenta de La Publicidad, 1847) 462.

15. "Carta de concierto para labrar una mina en el Cerro Potosí", Potosí, 1549. ANB, Sucre, Escribanía Pública y de Cabildo, ff. 118r-118v.

16. Juan Pimentel,"Sighting and Haunting of the South Sea: On Ponquiaco, Balboa, and What Maps Conceal”, Translating Nature. Cross-Cultural Histories of Early Modern Science, eds. Jaime Marroquín 
filosófica, lo secreto abarcaba aquello que estaba oculto por la naturaleza y que debía ser develado — para luego ser bien guardado - a través de una investigación táctica, a la manera de una cacería. ${ }^{17}$ Los "secretos de la naturaleza" de la cultura artesanal y naturalista europea se referían a problemas y perplejidades sobre propiedades y fenómenos de la materia, especialmente investigados por filósofos naturales, médicos, alquimistas y artistas. Bajo los reinados de Carlos V y Felipe II el motivo epistémico del secreto alcanzó una dimensión política y económica que tuvo repercusiones en las maneras de investigar y administrar las geografias americanas.

El lenguaje del secreto se tornó particularmente operativo en los procesos de construcción imperial. ${ }^{18}$ Los intereses por la filosofia natural, la alquimia, la ingeniería y la astrología se amalgamaron en la monarquía compuesta española con políticas de sigilo y cautela. ${ }^{19}$ Las investigaciones naturales, la innovación en procedimientos técnicos y las experimentaciones con la materia — que tanto éxito tuvieron a lo largo del siglo XVI en Europa con "libros de secretos" escritos por artesanos, ingenieros y médicos - encontraron una versión geográfica en las empresas de conocimiento de las tierras americanas. Bajo las políticas de conocimiento geográfico del Consejo de Indias, la búsqueda de los "secretos de la naturaleza" se transformó en la búsqueda por los "secretos de la tierra".

Relaciones y cuestionarios para expediciones por mar y tierra se realizaron durante la primera mitad del siglo bajo la motivación del secreto. Desde las primeras expediciones de conquista se observa el uso del secreto como una expresión de deseo por poseer y descubrir territorios y, con ellos, sus recursos y poblaciones. Por ejemplo, Fernández de Oviedo, quien hace amplio uso de la retórica de lo secreto en su obra, cuenta que en septiembre de 1513 Vasco Núñez de Balboa movilizó a

Arredondo y Ralph Bauer (Philadelphia: University of Pennsylvania Press, 2019) 39.

17. Sobre la cultura del secreto en la época moderna y la analogía con la "caza de la verdad", véase el estudio seminal de William Eamon, Science and the Secrets of Nature: Books of Secrets in Medieval and Early Modern Culture (Princeton: Princeton University Press, 1994) 271. Igualmente, sobre la tradición de lo oculto y lo abierto en la cultura del conocimiento en Europa, véase Pamela O. Long, Openness, Secrecy, Authorship. Technical Arts and the Culture of Knowledge from Antiquity to the Renaissance (Baltimore:The John Hopkins University Press, 2004).

18. Para un reciente estudio sobre el secreto en la vida política, véase Sylvain André y otros, dirs., "Arcana Imperii". Gouverner par le secret à l'époque moderne. France, Espagne, Italie (Paris: Les Indes Savantes, 2019). El gusto político por el secreto y el disimulo en la corte de Felipe II ha sido resaltado en la biografia de Geoffrey Parker, Imprudent King: A New Life of Phillip II (New Haven: Yale University Press, 2014).

19. Geografia, política y alquimia se tejen en el libro de Ralph Bauer, The Alchemy of Conquest. Science, Religion, and the Secrets of the New World (Charlottesville: University of Virginia Press, 2019). Sobre la producción y protección de la información cosmográfica véase Portuondo; sobre los secretos de la tierra como deseo de lo lejano, Paul Freedman, Lo que vino de Oriente. Las especias y la imaginación medieval (Valencia: Universitat de València. 2010) 31. De gran utilidad sigue siendo David C. Goodman, Power and Penury. Government, technology and science in Philip II's Spain (Cambridge: Cambridge University Press, 2002).Véase también Edward Peters, "The Desire to Know the Secrets of the World", Journal of the History of Ideas 62.4 (2001): 594. 
sus tropas con la esperanza de encontrar los secretos de la tierra escondidos en el Darién:

Con esperanza de los avisos que destos indios ya tenía Vasco Nuñez sabido y entendido en mucho secreto por sus lenguas, acordó de se partir [...] y salió de la villa de Santa María de la Antigua con ochocientos hombres, y embarcóse en un galeón y nueve canoas con esta gente, so color de buscar minas y inquirir los secretos de la tierra. ${ }^{20}$

De manera análoga, en la capitulación otorgada a Diego Velázquez en 1518 para ir, descubrir, y conquistar Cozumel y Yucatán se insiste en la importancia de reportar "los secretos de la tierra" que allí se encuentren. ${ }^{21}$ La búsqueda de los secretos de la tierra también aparece en la relación sobre la expedición de Magallanes escrita por Maximiliano Transylvanus. Magallanes intentaba convencer al entonces rey Carlos I de la existencia de un pasaje en el extremo sur de América que lo llevaría a Oriente, por lo cual presentó a su socio, el comerciante Cristóbal de Haro, como un conocedor que "había tenido contratación con los pueblos de los Sinas, y sabido y sido avisado por sus factores de los secretos y cosas de aquellas tierras de las partes orientales". ${ }^{22}$ A la par de esta secuencia, casi en el mismo momento, Hernán Cortés estaba intentando descubrir los secretos de la tierra de Moctezuma:

En esta gran ciudad estuve proveyendo las cosas que parecía que convenía al servicio de vuestra sacra majestad y pacificando y atrayendo a él muchas provincias y tierras pobladas de muchas y muy grandes ciudades, villas y fortalezas y descubriendo minas y sabiendo e inquiriendo muchos secretos de las tierras del señorío de este Muteczuma, como de otras que con él confinaban y él tenía noticia; que son tantas y tan maravillosas, que son casi increíbles. ${ }^{23}$

El lenguaje del "secreto de la tierra" entrañaba entonces la finalidad práctica de recolectar y construir conocimiento sobre la historia natural, la geografia, las

20. Gonzalo Fernández de Oviedo, Historia general y natural de las Indias, segunda parte, t. III (Madrid: Imprenta de la Real Academia de la Historia, 1853) 9. Cursivas de los autores.

21. Milagros delVas Mingo, Las capitulaciones de Indias en el siglo XVI (Madrid: Instituto de Cooperación Iberoamericana, 1986) 169-172.

22. Véase la relación escrita por Maximiliano Transylvanus sobre el descubrimiento de las islas Molucas. José Toribio Medina, Colección de documentos inéditos para la historia de Chile: desde el viaje de Magallanes hasta la batalla de Maipo: 1518-1818, t. I (Santiago: Imprenta Ercilla, 1888) 262.

23. Véase la "Segunda carta-relación de Hernán Cortés al Emperador: fecha segura de la Sierra á 30 de octubre de 1520". Pascual de Gayangos, comp., Cartas y Relaciones de Hernán Cortés al Emperador Carlos V (París: Imprenta de los Ferro-carriles, 1866) 113. Por otra parte, como indica Alessandra Russo, es importante conectar los "secretos" con los objetos dentro de esta expansión: "les progrès rapides de la conquête auraient été inconcevables si les Espagnols n'avaient pas pu compter sur ces objets 'stratégiques', qu'il s'agisse des panachés, des boucliers, des étendars en plumes, ou des 'cartes' indispensables pour pénétrer 'les nombreux secrets de la terre". Alessandra Russo, L'image intraduisible. Une histoire métisse des arts en Nouvelle-Espagne (1500-1600) (Paris: Les Presses du Réel, 2013) 64. 
potenciales riquezas y los modos de vida de las comunidades americanas. Pero indagar en los secretos de la tierra apuntaba no solo a la comprensión, sino también al poblamiento y al dominio hispánico en América. En esa medida, lo secreto adquirió una dimensión tanto epistémica como política. La búsqueda constante de dichos secretos conduciría a las autoridades del Consejo de Indias a elaborar cuestionarios metódicos para que navegantes, capitanes y autoridades locales dieran cuenta detallada y sistemática de las particularidades de la naturaleza americana con el fin de tomar decisiones. Este potente dispositivo del "secreto de la tierra" debe ligarse al largo proceso de confección de cuestionarios como modo de conocimiento geográfico, y que va desde Fernández de Oviedo entre 1520 y 1530 , pasa por Alonso de Santa Cruz en la década de 1550, hasta Juan de Ovando y Juan López de Velasco en la década de $1570 .{ }^{24}$

Las prácticas cosmográficas de Juan Ladrillero entre Panamá y Magallanes tuvieron su lugar dentro del marco epistémico y político de la búsqueda de secretos de la tierra. Ladrillero tuvo su fase de formación en la búsqueda y experiencia de esos secretos en las inmediaciones de la costa equinoccial del mar del Sur, cuando fue lugarteniente de Pascual de Andagoya en la gobernación de San Juan y, antes, cuando avanzó junto a Belalcázar desde Quito hacia el Norte. En 1536 este último emprendió una expedición con 300 hombres con el beneplácito de Francisco Pizarro y, ese mismo año, con Ladrillero fundaron la ciudad de Cali, donde comenzaría la construcción de la gobernación de Popayán. Como lo confirma un veterano capitán, curtido en los pesares de las guerras selváticas en el Nuevo Reino de Granada, Bernardo de Vargas Machuca, las avanzadas de conquista y pacificación no solo consistían en asuntos de guerra y paz, sino también en cálculos de latitud y longitud, en la traza y registro de caminos con brújula, en la "navegación en tierra" y en descripciones medioambientales; prácticas que la cosmografia proveía y que Ladrillero podía llevar a cabo. ${ }^{25}$ Precisamente, mientras estaba en Cali en 1539, Ladrillero se encontró con la expedición liderada por Juan de Vadillo —en la que participó Pedro Cieza de León- y que acababa de atravesar todo un brazo de la cordillera tropical desde Cartagena. En el encuentro, Ladrillero discutió con Vadillo sobre la ubicación de los ríos Darién y Cauca, y calculó distancias con el fin de demarcar las gobernaciones aledañas al mar del Sur. ${ }^{26}$

24. Sobre la recolección de la información geográfica y la paulatina sistematización a través de cuestionarios como los de Alonso de Santa Cruz o los de Juan de Ovando y Juan López de Velasco, véase Antonio Barrera-Osorio, "Empire and Knowledge: Reporting from the New World", Colonial Latin American Review 15.1 (2006):39-54; Raquel Álvarez Peláez, La conquista de la naturaleza americana (Madrid: Consejo Superior de Investigaciones Científicas, 1993). Además, la obra de referencia Francisco de Solano, ed., Cuestionarios para la formación de las Relaciones Geográficas de Indias. Siglos XVI-XIX (Madrid: Consejo Superior de Investigaciones Científicas, 1988).

25. Bernardo deVargas Machuca, Milicia y descripción de las Indias (Bogotá:Banco Popular / Universidad de los Andes, 2003) 133-134.

26. Gregorio Saldarriaga, “Transcripción de la relación del viaje del licenciado Joan de Vadillo entre San Sebastián de Urabá y Cali, 1539”, Boletín de Antropología 26.43 (2012): 42-65. 
Posteriormente, entre 1539 y 1541, Ladrillero estuvo al servicio del adelantado Pascual de Andagoya procurando fundar pueblos, pacificar poblaciones y custodiar la bahía de Buenaventura. Andagoya había recibido del rey el beneplácito para proclamar dominio sobre la gobernación de San Juan: un espacio incierto que tenía la ventaja - y la desventaja - de no tener confines claros, y de estar ubicado en un sector de ciénagas y manglares donde al menos cuatro ríos tenían el mismo nombre. ${ }^{27}$ En una carta al rey enviada en julio de 1539, Pascual de Andagoya escribió que en su expedición en busca de una entrada desde el mar del Sur hacia el interior de los Andes llevaba excelentes pilotos (probablemente Ladrillero) con quienes, dice, "entraré a saber los secretos de aquella tierra y enviaré la demarcación y información verdadera de todo lo que hubiere". ${ }^{28}$ Sobre este lugar en la costa, Andagoya agrega: "creo que será el mejor paraje y entrada de la tierra y, hecho donde mejor me pareciere un pueblo, entraré luego a saber los secretos de la tierra con el menos daño que me fuere posible de los naturales porque verdaderamente creo que sin llevar los gobernadores especial cuidado desto no pueden servir a Dios ni a vuestra majestad". ${ }^{29}$ Como se observa, los objetivos de poblar y proclamar dominio estaban explícitamente conectados con las motivaciones de conocer los secretos de la tierra.

La colaboración entre Andagoya y Ladrillero no duró mucho. Andagoya tomó posesión de la ensenada de la Cruz y fundó Buenaventura con Ladrillero. Luego lo nombró su teniente para ir hacia el interior andino y fundar la ciudad de Lile, a solo veinte leguas de Cali. Fernández de Oviedo cuenta que poco tiempo después Sebastián de Belalcázar, que recién había regresado de España, se enteró de la nueva entrada. Belalcázar se embarcó entonces rápidamente en Panamá con la intención de encontrarla y dirigirse hacia Popayán, para lo cual atravesó a la fuerza la gobernación de San Juan. Según Fernández de Oviedo, cuando Belalcázar finalmente encuentra el puerto de Buenaventura en la costa, Ladrillero, "con sentimiento" o favor hacia el gobernador de Popayán, le entrega toda la información de estos secretos de la tierra y le indica el camino por dónde entrar. Belalcázar y Andagoya se enfrentarían días después en el Monasterio de Nuestra Señora de la Merced. Allí tuvieron una larga disputa cosmográfica y política en la que compararon medidas, mapas y cédulas reales para dirimir cuáles eran los límites entre la gobernación de San Juan y la de Popayán. Entrada la noche, y "más acompañado de gente y armas que de letras", Belalcázar logró ganarse el favor de los hombres de Andagoya y consiguió apresarlo y enjuiciarlo por usurpación. ${ }^{30}$

En el relato de Fernández de Oviedo queda flotando sobre Ladrillero un cierto halo de conspirador. Sin embargo, más adelante, el mismo Fernández de Oviedo

27. Marta Herrera Ángel, El conquistador conquistado. Awás, Cuayquer y Sindaguas en el Pacífico colombiano, siglos XVI-XVIII (Bogotá: Ediciones Uniandes, 2016) 80-85.

28. "Carta al rey CarlosV de Pascual de Andagoya", 1539. Raúl Porras Barrenechea, Cartas del Perú, 1524-1543 (Lima: Sociedad de Bibliófilos Peruanos, 1959) 370. Cursivas de los autores.

29. Porras Barrenechea 370. Cursivas de los autores.

30. Fernández de Oviedo, Historia general y natural, tercera parte, 128-139. 
también cuenta que Ladrillero continuó en la región aledaña a Buenaventura, pobló el río San Juan y logró mantener la paz con los indígenas de allí. ${ }^{31}$ Este tipo de posición interesada muestra el talante pragmático y calculador de Ladrillero que se vería de nuevo cuando en 1545 testificara en Anserma en contra de la aplicación de las Leyes Nuevas y a favor del sistema de las encomiendas. En su declaración Ladrillero da a entender que estaba de lleno en el negocio de la minería del oro, pero que, paradójicamente, se encontraba endeudado, pues las provisiones eran demasiado costosas. Es por eso que alega que si "se les quitasen los indios [a los conquistadores] por razón de lo susodicho se les haría mucho agravio y quedarían pocos con indios y no tendrían con qué pagar lo que deben y que los acreedores está claro que procurarían de cobrar lo que les deben y les molestarían y echarían en cárceles". ${ }^{32}$ Ahora bien, aunque Ladrillero no apoyó las Leyes Nuevas, es importante señalar que tampoco apoyó la rebelión pizarrista. Cieza de León cuenta que Ladrillero incluso intentó ayudar a huir por el camino de Popayán hacia Buenaventura al generalVela Núñez, hermano del entonces virrey Blasco Núñez. Un plan fallido, ya que el general fue apresado por los capitanes de Gonzalo Pizarro y Ladrillero tuvo que salir huyendo selva adentro, "muy perseguido de un tigre, que fue cosa extraña no despedazarle, y constreñido de necesidad y por el hambre" terminó por entregarse y fue llevado a Panamá. ${ }^{33}$ Pero al año siguiente, en 1546, Ladrillero está de nuevo al servicio de las autoridades de la Corona, pues se une al recién enviado presidente Pedro La Gasca para combatir a Gonzalo Pizarro en el Perú.

La misión de exploración de Juan Ladrillero en el sur de América entre los años 1557 y 1559 estuvo ligada a una misión específica que como veremos a continuación también se enmarcó en la pretensión de conocer los secretos de la tierra al sur del estrecho de Magallanes.

\section{Develar el secreto del estrecho de Magallanes}

La navegación de Ladrillero por el Estrecho tuvo la misión de terminar de develar sus secretos geográficos. El interés por explorar esta región se remontaba a 1520 y a la imposibilidad de haber conocido la totalidad de sus parajes, particularmente los territorios al sur del Estrecho, asociados a una idea de riqueza única que perduró por siglos. ${ }^{34}$ Desde la expedición de Fernando de Magallanes, al menos cuatro

31. Fernández de Oviedo, Historia general y natural, tercera parte, 134.

32. "Informaciones de oficio y parte:Villa de Santa Ana de Anserma por su procurador Melchor de Santiago, 1545”. AGI, Sevilla, Santa Fe, 122, n. 15, ff. 1r-36r. Ladrillero aparece años más tarde, en 1553, declarando en contra de la provisión real para abolir el servicio personal indígena.Véase Carlos Sempat Assadourian, "La renta de la encomienda en la década de 1550: piedad cristiana y desconstrucción", Revista de Indias 48.182-183 (1988): 139-143.

33. Pedro Cieza de León, Obras completas. Las Guerras Civiles Peruanas, t. II (Madrid: Consejo Superior de Investigaciones Científicas / Instituto Gonzalo Fernández de Oviedo, 1985) 469.

34. James Burgh, La cité des Césars. Une utopie en Patagonie (Paris: Utz / Éditions UNESCO, 1996); Patricio Estellé y Ricardo Couyoudmdjian, "La ciudad de los Césares: origen y evolución de 
expediciones intentaron navegar y situarse en la zona sin éxito. Entre dichas expediciones fallidas estuvieron las de Francisco García Jofré de Loayza (1525-1526), quien iba con Juan Sebastián Elcano, la de Simón de Alcazaba (1535), la de León Pancaldo (1538) y la de Francisco Camargo (1540). ${ }^{35}$

Fue la conquista de Chile, a partir del año 1540, la que creó las condiciones para la apropiación del Estrecho. Pedro de Valdivia deseaba construir allí un "nuevo extremo", un nuevo límite-puerto para controlar los pasos hacia las distintas partes del mundo. ${ }^{36}$ Valdivia tenía claro cuáles eran las principales razones para extender la jurisdicción de Chile hacia el sur y navegar el estrecho de Magallanes:

por tres causas, dejadas las demás que se podían dar. La primera, porque toda esta tierra y Mar del Sur la tendrá Vuestra Alteza en España y ninguno se atreverá a hacer cosa que no deba; la segunda, que se tendrá muy a la mano toda la contratación de la especería, y la tercera, porque se podrá descubrir y poblar esa otra parte del Estrecho que, según estoy informado, es tierra muy bien poblada. ${ }^{37}$

El intento de anexión del Estrecho fructificó en 1552 cuando la monarquía visó la solicitud de Valdivia que había sido llevada a la Corte por su mano derecha, Jerónimo de Alderete. La respuesta tardó en total un año en resolverse, justo en el momento en que Valdivia muere en una batalla con los "araucanos" en 1553. Debido a la muerte del gobernador de Chile y al interés de los rivales de España por apropiarse del Estrecho, las autoridades toman una serie de decisiones geopolíticas para toda la zona con el fin de dar seguridad y marcar su posición. ${ }^{38}$

una leyenda", Historia 7 (1968): 283-309; María Ximena Urbina, "La expedición de John Narborough a Chile, 1670: defensa de Valdivia, rumores de indios, informaciones de los prisioneros y la creencia en la ciudad de los Césares", Magallania 45.2 (2017): 11-36.

35. Para tener una idea general de esto, véase Pablo Emilio Pérez-Mallaína Bueno, Naufragios en la Carrera de Indias durante los siglos XVI-XVII. El hombre frente al mar (Sevilla: Editorial Universidad de Sevilla, 2015); Carlos Bascuñan y otros, Naufragios en el Océano Pacífico Sur, t. I (Santiago: Taurus / Dirección de Bibliotecas, Archivos y Museos / Centro de Investigaciones Diego Barros Arana, 2011).

36. Sobre la importancia geopolítica de los puertos y la idea de América como trampolín para la expansión hacia Asia, véase Louise Bénat-Tachot, "La Corogne et Séville: les horizons de l'expansion maritime espagnole (14921550)", eSpania 22 (2015). DOI: https://doi.org/10.4000/e-spania.25043 (17/04/2019).

37. "Carta de Pedro de Valdivia al príncipe Maximiliano", Santiago, 26 de octubre de 1552. Miguel Rojas-Mix, ed., Cartas de Don Pedro de Valdivia que tratan del descubrimiento y conquista de la Nueva Extremadura (Barcelona: Editorial Lumen, 1991) 180-181.

38. El tema de los "rivales de España" debe relativizarse. Desde la expedición de Magallanes casi todos los reinos europeos tuvieron algún grado de influencia o representantes en las expediciones que se fueron organizando desde España para descubrir América y en especial la zona sur del Atlántico. Un ejemplo concreto es el de Ulrich Schmidel.Véase Ulrich Schmidel, Voyage curieux au río de la Plata (1534-1554) (Paris: Utz / Éditions UNESCO, 1998). Sobre el interés francés en la región austral, véanse los trabajos de André Thevet, Le Brésil d'André Thevet: les singularités de la France antarctique (1557) (Paris:Éditions Chandeigne, 2011) 287; Guillaume Le Testu, Cosmographie 
Las nuevas estrategias esbozadas en la península ibérica y organizadas en el Perú se pueden resumir en dos fases. La primera consistió en un cambio de jefaturas en el virreinato del Perú en 1556. Asumió un nuevo virrey, Andrés Hurtado de Mendoza, y un nuevo gobernador para Chile, García Hurtado de Mendoza, hijo del virrey, ya que Jerónimo de Alderete murió en 1556 durante el viaje para tomar posesión, luego de la muerte de Pedro de Valdivia. La segunda fase, entre 1557 y 1559, apuntó a la aplicación de una estrategia de observación y posicionamiento por medio de una doble expedición que fuera al Estrecho por mar, liderada por Ladrillero, y por tierra, encabezada por García Hurtado de Mendoza. ${ }^{39}$

El Consejo de Indias en una carta al rey escrita en 1558, mientras ocurría la expedición de Ladrillero, expuso las razones de esta estrategia geopolítica. Los argumentos apuntaban tanto al control y al estímulo de la conexión continental como al fortalecimiento de la seguridad ante las amenazas externas y posibles rebeliones internas. ${ }^{40} \mathrm{La}$ carta demuestra las múltiples escalas que se le atribuían al pasaje-mundo del estrecho de Magallanes:

Lo primero, porque vuestra majestad tiene al presente muy quieta y pacífica toda la Mar del Sur [...] y si el dicho Estrecho se navegase y descubriese, podrían entrar por él navíos de franceses y de otros enemigos e inquietarían y robarían todas las costas de Chile y del Perú y podrían llegar hasta la Nueva España por la Mar del Sur [...] Lo segundo, porque como la tierra del Perú está siempre tan inquieta, los que se alterasen contra el servicio de vuestra majestad podrían meter valedores por el dicho Estrecho de otros príncipes, lo cual al presente no se puede hacer por no saberse la navegación [...] Lo tercero, porque la puerta para entrar ahora en el Perú solo es por el Nombre de Dios, y desde allí se ha de ir por tierra a Panamá que está en la Mar del Sur. ${ }^{41}$

Universelle selon les navigateurs tant anciens que modernes (Paris: Arthaud / Direction de la Mémoire, du Patrimoine et des Archives / Carnets des Tropiques, 2012).

39. Para la campaña por tierra el nuevo gobernador dispuso de 500 hombres que trajo desde Perú y de ilustres personajes que lo acompañaron desde España como Alonso de Ercilla, quien en su obra narra cómo la expedición por tierra no pudo avanzar porque los indígenas no lo permitieron. Por lo demás, Ercilla no menciona a Ladrillero en ninguna de las múltiples ediciones de La Araucana. Ercilla regresó a España antes de que Ladrillero volviera de su navegación y, quizás, la información del derrotero no tendría en la península ibérica la circulación que sí tuvo en América. Diego Barros Arana habla más bien de cierta reserva por la importancia de las informaciones. El historiador señala que autores como Fernández de Navarrete y Humboldt criticaron a Ercilla por no haber hecho mayor referencia a la expedición por mar. Diego Barros Arana, Historia General de Chile, t. II (Santiago: Editorial Universitaria / Centro de Investigaciones Diego Barros Arana, 2000) 153.

40. Desde 1540, la piratería comienza a tener un rol preponderante cuando España decide no dar más cabida comercial a los mercaderes ingleses y franceses en Andalucía. Lourdes de Ita Rubio, Viajeros isabelinos en Nueva España (Morelia / México: Universidad Michoacana de San Nicolás de Hidalgo / Fondo de Cultura Económica, 2001) 27; Nara Fuentes Crispín, Periplos ilustrados, piratas y ladrones en el Caribe colonial (Bogotá: Universidad Nacional de Colombia, 2013).

41. Consejo de Indias, "Sobre los descubrimientos en el Estrecho de Magallanes", Valladolid, 5 de mayo de 1558. AGI, Sevilla, Indiferente, 738, n. 26, f. 1. 
Pero donde mejor se expresan las razones de la expedición por mar y tierra hacia el estrecho de Magallanes es en una real cédula hecha en la ciudad de Valladolid, datada el 29 de mayo de 1555. El documento estaba dirigido al nuevo gobernador de Chile que tenía que ponerlo en práctica. El escrito solicitaba al gobernador ir al estrecho de Magallanes y entender los "secretos” que había en esa zona:

Nuestro gobernador de la provincia de Chile, ya sabéis cómo os hemos proveído de la dicha gobernación hasta el Estrecho de Magallanes y porque nos deseamos saber las tierras y poblaciones que hay de la otra parte del dicho Estrecho y entender los secretos que hay en aquella tierra, os mando que desde las dichas provincias de Chile enviéis algunos navíos a tomar noticia y relación de la calidad de aquella tierra, y de la utilidad de ella y a saber y entender qué poblaciones y gente hay en ella, y qué cosas se crían y qué manera de vivir y costumbres tienen los que la habitan, y si es isla, y qué puertos hay en ella, y de qué manera se navega aquella costa, y si hay monzones o corrientes, y a qué partes o qué curso hacen, y qué manera de religión tienen, y si son idolatrías, y qué manera tienen de gobierno, y qué leyes y costumbres, y qué minas y metales, y qué otras cosas que sean provechosas hay en la dicha tierra, y si comen carne humana, y si hay o hubo entre ellos memoria de nuestra religión o de otra secta, y si tienen reyes por elección o suceden por herencia o derecho de sangre, y qué tributos pagan a sus reyes, y entendido el secreto de todo $y$ sabido lo susodicho nos enviaréis relación de ello para que, vista, mandemos proveer en lo que toca a su población lo que viéramos más convenir. ${ }^{42}$

En esta cédula se constata lo que antes afirmábamos: que el dispositivo del "secreto de la tierra" está ligado al modo de conocimiento por cuestionario. La cédula se presenta como una instrucción donde se exige que se haga una detallada relación que incluya los rubros descriptivos que revelen los secretos de la tierra, es decir, que den cuenta de la poblaciones, costumbres, plantas y animales que allí se generan, manera de navegar en ese lugar, cualidades atmosféricas, recursos naturales, entre otros. ${ }^{43}$

El documento muestra cómo el secreto funciona como un creador de espacio, de un plus ultra, de un más allá que justifica acciones en tierras desconocidas o especuladas. El fomento del "secreto del Estrecho" se torna capital en la formación de la Terra Australis Incognita y en sus cartografias de espacios en blanco. ${ }^{44}$ Además,

42. Utilizamos una copia de la original hecha en Valladolid. "Cédula Real al Gobernador de Chile", Bruselas, 20 de diciembre de 1558. AGI, Sevilla, Patronato, 32, r. 4. Cursivas de los autores.

43. La vecindad entre esta real cédula y los futuros cuestionarios geográficos es notable. Para el momento en que se expide la real cédula, el cosmógrafo Alonso de Santa Cruz tenía fuerte injerencia en la confección de instrucciones para la descripción geográfica de las Indias. Véase, por ejemplo, su "Parecer sobre descubrimientos en las Indias". Mariano Cuesta Domingo, Alonso de Santa Cruz y su obra cosmográfica, t. I (Madrid: Consejo Superior de Investigaciones Científicas / Instituto Gonzalo Fernández de Oviedo, 1983) 67-72; Portuondo 110-115.

44. Sobre lo incógnito, los espacios en blanco y la construcción continental de América, véase Carla Lois, Terrae incognitae. Modos de pensar y mapear geografías desconocidas (Buenos Aires: Eudeba, 2018); Carla Lois, "Quinta pars o terrae incognitae? La cuestión de la verosimilitud en la representación cartográfica de lo desconocido", Terra Brasilis 4 (2015). DOI: https://doi.org/10.4000/terrabrasilis.1084 
el secreto se torna incentivo para conocer algo que pueda dar algún rédito, así como un dispositivo de comprensión de la historia y del territorio de otras culturas. Como se aprecia, la búsqueda del "secreto de la tierra" hace parte del proceso de construcción del territorio americano y, particularmente, del pasaje-mundo que Juan Ladrillero debía describir.

\section{La relación de Juan Ladrillero}

A diferencia de sus experiencias en las costas equinocciales, de las que no se conocen hasta hoy reportes firmados por él, Ladrillero dejó una extensa relación sobre su circulación por el Estrecho. Ladrillero llegó a Chile en febrero de 1557. Desde la ciudad de La Serena y con 60 hombres zarpó hacia la ciudad de Valdivia. En noviembre, desde dicha ciudad que dependía directamente del virreinato del Perú, comenzó su periplo hacia el Estrecho. Dos naves y un bergantín conformaban la expedición: la San Luis, capitaneada por él, y la San Sebastián, capitaneada por Francisco Cortés Ojea, quien había participado en una excursión anterior, liderada por el capitán Ulloa en 1553. ${ }^{45}$ También los acompañó un bergantín (San Salvador) financiado por su propio capitán Diego Gallego. Las dos embarcaciones que acompañaban a Ladrillero se perdieron en el camino y regresaron a la ciudad de Concepción dejando una extensa relación. ${ }^{46}$

El manuscrito de Ladrillero es un registro que se puede leer en función de la cédula real de 1555 y, por extensión, de los rubros del cuestionario que buscaban conocer los secretos de esa tierra. La relación sitúa los puertos, bahías, ensenadas, canales, cabos, islas, lagos, ríos y montañas desde la ciudad de Valdivia hasta el estrecho de Magallanes. Se reúnen datos de navegación, apreciaciones sobre el clima, calidad de las tierras y de las personas. El propio Ladrillero puso en evidencia que él estaba respondiendo a una instrucción a modo de formulario:

(14/05/2019); Alfred Hiatt, Terra Incognita. Mapping the Antipodes before 1600 (Londres: British Library, 2008). Sigue siendo muy útil Isabelle Laboulais-Lesage, dir., Combler les blancs de la carte. Modalités et enjeux de la construction des savoirs géographiques (XVIIe-XXe siècle) (Estrasburgo: Presses Universitaires de Strasbourg, 2004).

45. Esta expedición y la de Magallanes son las únicas que Ladrillero nombra en su relación. De esta relación, escrita por Ladrillero en 1559 probablemente en Valdivia, se conserva en el AGI una copia hecha por Antonio Manuel de Guevara en la ciudad de Valladolid. Juan Ladrillero, "Descripción del viaje de Juan Ladrillero: Estrecho Magallanes" [Valladolid, copia de ca.1573 a partir del original de 1559]. AGI, Sevilla, Patronato, 33, n. 1, r. 1, ff. 11v-12r y 27v.

46. Véase la relación dejada por Francisco Cortés de Hojea que se encuentra en el AGI bajo el nombre: "Derrotero y viaje de Juan Ladrillero: Estrecho de Magallanes" [Valdivia, 1 de octubre de 1558]. AGI, Patronato Real, 32, r. 5. Una transcripción completa y modernizada de esta relación se encuentra en el texto de Mauricio Onetto Pavez, "Los 'descubrimientos' del estrecho de Magallanes. La relación de los ayudantes del piloto-cosmógrafo Juan Ladrillero, 1557-1558”, Anales de Literatura Chilena (2020). [En prensa]. 
Figura 1. Trayecto de la expedición de Ladrillero desde la ciudad de Valdivia hasta la boca norte del estrecho de Magallanes, 1557-1559

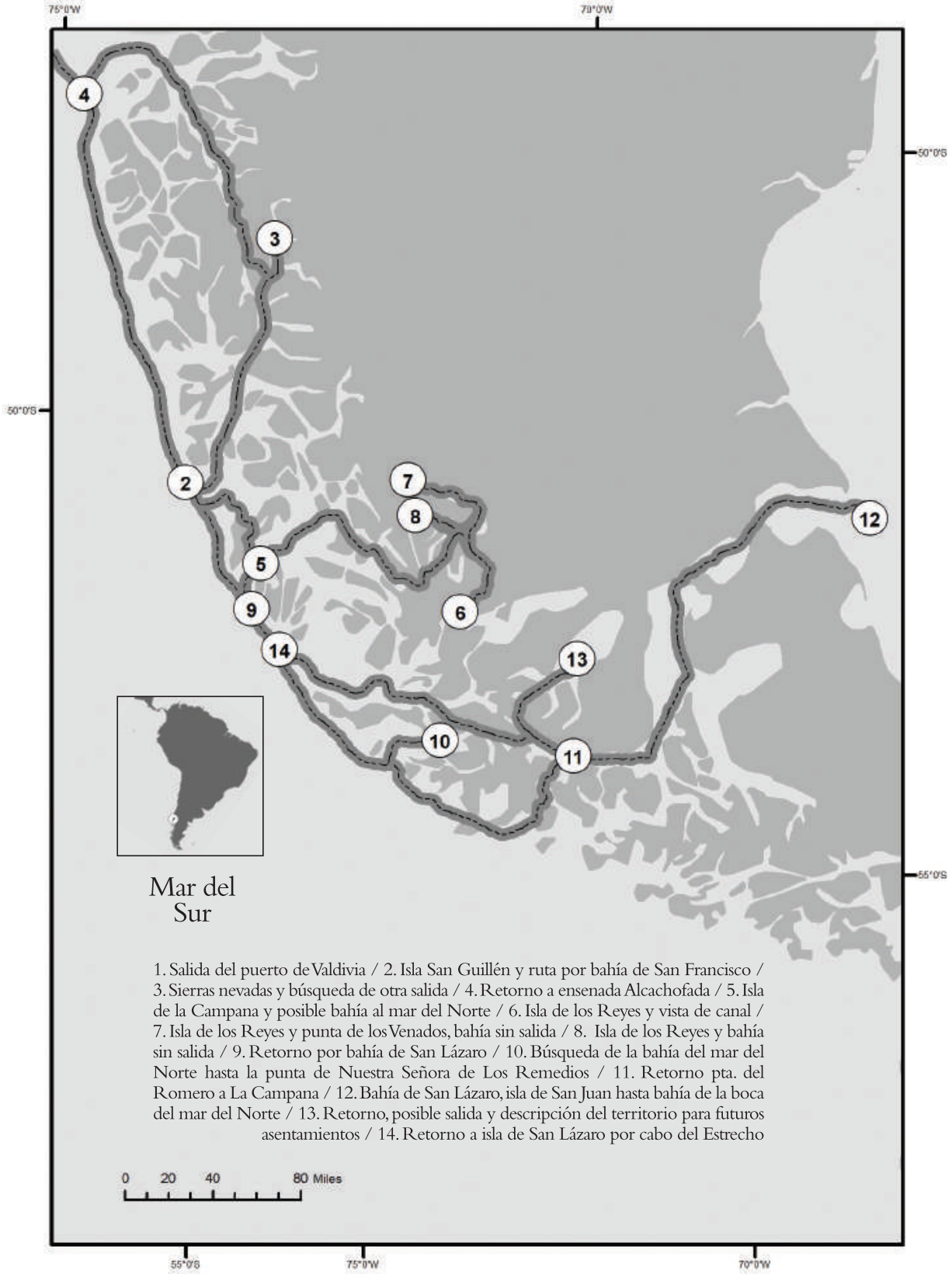

Fuente: Elaborado por Luis Valenzuela Olivares con base en AGI, Sevilla, Patronato, 33, n 1, r 1; Anuario Hidrográfico de la Marina de Chile (Santiago) 1880: 453-525. 
Relación, derrotas y altura y señales de tierras, y cualidad de ellas, y traje y manera de la gente de cada provincia o bahía, y los tiempos que reinan en ella en todos los meses de el año; y asimismo para que más bien entendida sea, y rehablando en las derrotas y altura de la costa, de cómo se corre y el altura en que está, y señales de las bahías y puertos, y la distancia de lo que cada una bahía entra en la tierra adentro, y cómo se corre, y los brazos que en ellas hay y la cualidad de la gente y traje que en cada una acostumbran a traer, y las armas que tienen para ofender. ${ }^{47}$

El documento nos muestra de entrada el método clásico, ptolemaico, de la descripción geográfica que se ocupa de los aspectos de la cantidad y la posición, así como de la cualidad y la experiencia. En efecto, además de anotar la ubicación, la dirección de la derrota y el cálculo de la distancia, la relación se propone transmitir las "señales" de la tierra, es decir, aquellas particularidades de las formas o alturas de bahías, islas o montes que, perceptibles desde un barco, pudieran servir para la orientación de futuros navegantes. La "autopsia", el ver y experimentar por sí mismo, es en esta relación un claro compromiso de Ladrillero con el empirismo crítico de la tradición cosmográfica del siglo XVI. ${ }^{48}$ En esa medida, no cabía la especulación. Especular significaba arriesgarse a construir malas señales para la navegación del Estrecho. Es por esta razón que Ladrillero dejó en claro que no describiría aquello que no había visto o caminado como, por ejemplo, cuando pasa por "otras canales y ancones" cerca de la isla de la Campana, pero que "por no las haber andado por de dentro dellos, de ellos no hablaré". ${ }^{49}$

Además del cuidado en la relación de Ladrillero por asuntos de posición y de cualidad, es de resaltar el interés por las comunidades en las que también insistía la cédula real de 1555. Si bien la indicación de estos grupos también servía para crear una referencia en la navegación, la mirada "etnográfica" tenía ante todo una finalidad política que consistía en señalar los lugares habitados en los que podrían fundarse pueblos, crear encomiendas, construir misiones o, en su defecto, declarar guerra justa. Es así como, por ejemplo, Ladrillero describió las personas con las que él y su tripulación convivieron entre los meses de marzo y julio durante el invierno de 1558:

La gente desta boca del Estrecho, a la parte de la mar del Sur, son bien dispuestos de cuerpo. Así los hombres, como las mujeres, y los hombres son soberbios y de grandes fuerzas; y las mujeres bien agestadas. Su traje es cueros de lobos y de nutrias; atados por las gargantas, que les llegan hasta las rodillas, mantiénense de lobos marinos que matan, y de marisco, y pescado, y ballenas, que dan en su tierra; y cómenlo crudo, y otras veces los asan poca cosa. Sus armas son unos dardillos de madera blanca, y dagas de huesos de ballena y de animales. Traen canoas de cáscaras de árboles

47. Ladrillero f. $2 \mathrm{v}$.

48. Sobre la tradición empírica en las prácticas de conocimiento en España, véase Antonio BarreraOsorio, Experiencing Nature: The Spanish American Empire and the Early Scientific Revolution (Austin: University of Texas Press, 2006). Para una historia de la cosmografía en la temprana Edad Moderna en Europa, véase Jean-Marc Besse, Les grandeurs de la Terre. Aspects du savoir géographique à la Renaissance (Lyon: ENS Éditions, 2003).

49. Ladrillero f. $9 \mathrm{v}$. 
cosidas con barbas de ballena. No tienen asiento en ninguna parte; y dondequiera que llegan, ponen unas varas, y encima unas cortezas de árboles, con que se reparan del agua y del viento. ${ }^{50}$

A pesar de los silencios, elipsis y omisiones recurrentes en el texto, el rol de los habitantes del Estrecho fue imprescindible para realizar el reconocimiento. Es así como, por ejemplo, gracias a "una india que por guía llevaba" Ladrillero pudo dirigirse hacia las tierras al sur del Estrecho, seguir un profundo canal que se comunicaba con otros canales y donde reconocieron muchas islas y altas "sierras nevadas". ${ }^{51}$ A diferencia del topógrafo que con su objeto-paisaje debe registrar en solitario sus anotaciones, un cosmógrafo como Ladrillero requería informantes para desarrollar su trabajo de develar el "secreto de la tierra". ${ }^{52}$

La lectura y análisis de esta relación nos permite distinguir que responde a tres grandes objetivos: expandir el territorio y crear un espacio austral por descubrir, orientar para una navegación segura y, por último, contribuir a la actualización del Padrón Real. El principal y primero fue "acabar de descubrir el Estrecho de Magallanes, y tierra desde los últimos límites de las provincias y gobernación de Chile, hasta el dicho Estrecho". ${ }^{53}$ No solo trataba de descubrir completamente el territorio de Chile y el Estrecho, sino de terminar de dibujar el territorio americano y conectarlo en su expansión. La expedición era parte de una política expansiva al mismo tiempo que de reconocimiento y protección. Testimonios posteriores, como el de Bautista Ventura en 1561, certifican el potencial expansivo que buscaba la excursión de Ladrillero: "porque navegándose el dicho Estrecho esta tierra del Perú y la del Chile irán en grande aumento y crecimiento". 54

El segundo objetivo fue aportar información para la navegación, definida como compleja por su clima cambiante, grandes vientos y corrientes: "y porque más claridad haya de este Estrecho para que los que por él hubieren de ir y venir [...] y para que los navegantes tengan más claridad por dónde se rijan" ${ }^{55}$ Ladrillero promovía una especie de "orden" por el cual debían navegar tanto los que "vinieren de Chile o del Perú" como los de "España por el Estrecho". Para ello, realizó una síntesis de las rutas que se debían tomar, resumió cada lugar por donde las embarcaciones tenían que pasar rápidamente o detenerse según la particularidad de la geografia. También puntualizó algunas informaciones sobre las corrientes, climas y vientos. La labor de Ladrillero era crear puntos de seguridad para una navegación más exitosa, una de las consignas estipuladas por la Casa de Contratación para los

50. Ladrillero f. $16 \mathrm{v}$.

51. Ladrillero ff. $18 \mathrm{r}-18 \mathrm{v}$.

52. Frank Lestringant, L'atelier du cosmographe, ou l'image du monde à la Renaissance (Paris: Albin Michel, 1991) 44.

53. Ladrillero f. 3r.

54. Testimonio de Bautista Ventura en las Probanza de los méritos y servicios de don García de Mendoza y Manrique, 7 de mayo de 1561. Medina, Colección de documentos, t. XXVII, 159-160.

55. Ladrillero ff. $2 \mathrm{r}$ y $21 \mathrm{v}$. 
cosmógrafos: 56 "me parece que irán con más seguridad, mediante Dios y su Bendita Madre [...] Por cabo y por la orden que digo, irán con menos trabajo, y más sin riesgo". 57

El tercer objetivo es quizás más especulativo. Creemos que la relación de Ladrillero también ayudaba a actualizar el Padrón Real y, en especial, la ruta que iba desde la boca del mar del Norte hasta las costas de Nueva España, pasando por los puertos del Perú y por Panamá. ${ }^{5}$ En efecto, el Padrón Real, además de ser un gran repositorio de mapas, estaba concebido para poder incluir registros textuales tales como derroteros, tablas de posiciones y relaciones en correspondencia con las instrucciones y con los cuestionarios geográficos. Algunos autores sugieren incluso que el documento de Ladrillero habría permitido realizar correcciones a mapamundis como el de Sancho Gutiérrez. ${ }^{59}$

\section{Consideraciones finales}

Juan Ladrillero fue un actor estratégico en los procesos de conquista en América y de construcción del Imperio español durante la primera mitad del siglo XVI. A través de las fuentes analizadas la figura de Ladrillero aparece como instancia de enlace entre dos pasajes-mundo americanos, entre dos entornos de circulación con dimensiones globales. Al menos en dos oportunidades este piloto y capitán participó en expediciones en las cuales el "secreto de la tierra" operaba como un dispositivo tanto de conocimiento geográfico como de comprensión geopolítica. En estas ocasiones Ladrillero era el agente que respondía y aplicaba a las instrucciones y expectativas que se enviaban desde el Consejo de Indias para llevar a cabo el proyecto de conocimiento geográfico a distancia. En su relación sobre la navegación por el estrecho de Magallanes, Ladrillero logró responder desde sus habilidades de piloto y cosmógrafo práctico a las exigencias de la cédula real de 1555, que pedía conocer los secretos de la tierra de ese pasaje-mundo. Por medio de este derrotero que circularía por las audiencias de los virreinatos americanos se redescubre el

56. Sánchez Martínez, "Los artífices del Plus Ultra" 623.

57. Ladrillero ff. $28 \mathrm{r}-28 \mathrm{v}$ y $29 \mathrm{r}$.

58. Sobre el Padrón Real, véase José María García Redondo, Cartografía e imperio. El Padrón Real y la representación del Nuevo Mundo (Madrid: Ediciones Doce Calles, 2018); Antonio Sánchez Martínez, La espada, la cruz y el Padrón. Soberanía, fe y representación cartográfica en el mundo ibérico bajo la Monarquía Hispánica, 1503-1598 (Madrid: Consejo Superior de Investigaciones Científicas, 2013). Respecto al Padrón Real, Arndt Brendecke señala que: "Se trata de un sistema de aprendizaje [...] debía contribuir a que cada experiencia particular ayudara a elevar el saber compartido a un nivel un poco más alto y, en consecuencia, a no tener que repetir errores. Mejorar el saber náutico se concebía, por lo tanto, como una tarea colectiva y un proceso a largo plazo de mejoramiento gradual, cuyo objetivo no era la verdad, sino actuar con seguridad sobre la base del conocimiento reunido por todos". Brendecke 176.

59. Véase Rodrigo Moreno Jeria, "El estrecho de Magallanes como antesala del Pacífico: evolución cartográfica y toponimia entre los siglos XVI y comienzos del XVIII", Anuario de Estudios Americanos 70.2 (2013): 421. 
Estrecho para volver a darle relevancia, con lo que se deja ver que hay "más" por aprovechar y que, más allá, al sur, las tierras esperaban ser exploradas y pobladas.

Por otra parte, el estudio de la figura de Ladrillero nos lleva a pensar más allá de él mismo, pues constata la estrecha conexión geopolítica entre los pasajes-mundo de Panamá y Magallanes. Dos enclaves prácticos y concretos por medio de los cuales espacios locales americanos alcanzaban dimensiones no solo hemisféricas, sino también globales. Adicionalmente, a través de Ladrillero es posible confirmar la utilidad historiográfica de estudiar los procesos de conquista junto con los procesos de construcción y circulación del conocimiento. Pasajes-mundo, secretos de la tierra y agentes como Juan Ladrillero son a la vez instancias de acción política y epistémica.

\section{Fuentes}

\section{Manuscritas}

Archivo General de Indias, Sevilla (AGI)

Indiferente

Panamá

Patronato

Santa Fe

Archivo Nacional de Bolivia, Sucre (ANB)

Escribanía Pública y de Cabildo

\section{Impresas}

Acosta, Josef de. Historia Natural y Moral de las Indias. Madrid: Consejo Superior de Investigaciones Científicas, 2008.

Castellanos, Juan de. Elegías de varones ilustres de las Indias. Tomo 4. Madrid: Imprenta de La Publicidad, 1847.

Cieza de León, Pedro. Crónica del Perú. El señorío de los Incas. Caracas: Biblioteca de Ayacucho, 2005.

- Obras completas. Las Guerras Civiles Peruanas. Tomo II. Madrid: Consejo Superior de Investigaciones Científicas / Instituto Gonzalo Fernández de Oviedo, 1985.

Fernández de Oviedo, Gonzalo. Historia general y natural de las Indias. Segunda parte.Tomo III. Madrid: Imprenta de la Real Academia de la Historia, 1853. . Historia general y natural de las Indias. Tercera parte. Madrid: Imprenta de la Real Academia de la Historia, 1855.

Gayangos, Pascual de. Comp. Cartas y Relaciones de Hernán Cortés al Emperador Carlos V. París: Imprenta de los Ferro-carriles, 1866.

Le Testu, Guillaume. Cosmographie Universelle selon les navigateurs tant anciens que 
modernes. Paris: Arthaud / Direction de la Mémoire, du Patrimoine et des Archives / Carnets des Tropiques, 2012.

Medina, José Toribio. Colección de documentos inéditos para la historia de Chile: desde el viaje de Magallanes hasta la batalla de Maipo: 1518-1818. Tomo I. Santiago: Imprenta Ercilla, 1888.

- Colección de documentos inéditos para la historia de Chile. Desde el viaje de Magallanes hasta la batalla de Maipo: 1518-1818. Tomo XXVII. Santiago: Imprenta Elzeviriana, 1901.

Porras Barrenechea, Raúl. Cartas del Perú, 1524-1543. Lima: Sociedad de Bibliófilos Peruanos. 1959.

Rojas-Mix, Miguel. Ed. Cartas de Don Pedro de Valdivia que tratan del descubrimiento y conquista de la Nueva Extremadura. Barcelona: Editorial Lumen, 1991.

Saldarriaga, Gregorio. "Transcripción de la relación del viaje del licenciado Joan de Vadillo entre San Sebastián de Urabá y Cali, 1539”. Boletín de Antropología 26.43 (2012): 42-65.

Schmidel, Ulrich. Voyage curieux au río de la Plata (1534-1554). Paris: Éditions Utz / Éditions UNESCO, 1998.

Thevet,André. Le Brésil d'André Thevet: les singularités de la France antarctique (1557). Paris: Éditions Chandeigne, 2011.

Vargas Machuca, Bernardo de. Milicia y descripción de las Indias. Bogotá: Banco Popular / Universidad de los Andes, 2003.

\section{Revistas}

Anuario Hidrográfico de la Marina de Chile (Santiago) 1880.

\section{Bibliografía}

Álvarez Peláez, Raquel. La conquista de la naturaleza americana. Madrid: Consejo Superior de Investigaciones Científicas, 1993.

André, Sylvain y otros. Dirs. "Arcana Imperii”. Gouverner par le secret à l'époque moderne. France, Espagne, Italie. Paris: Les Indes Savantes, 2019.

Barrera-Osorio, Antonio. "Empire and Knowledge: Reporting from the New World”. Colonial Latin American Review 15.1 (2006): 39-54.

. Experiencing Nature: The Spanish American Empire and the Early Scientific Revolution. Austin: University of Texas Press, 2006.

Barros Arana, Diego. Historia General de Chile. Tomo II. Santiago: Editorial Universitaria / Centro de Investigaciones Diego Barros Arana, 2000.

Bascuñan, Carlos y otros. Naufragios en el Océano Pacífico Sur. Tomo I. Santiago: Taurus / Dirección de Bibliotecas, Archivos y Museos / Centro de Investigaciones Diego Barros Arana, 2011.

Bauer, Ralph. The Alchemy of Conquest. Science, Religion, and the Secrets of the New World. Charlottesville: University of Virginia Press, 2019. 
Becker, Bertha Koiffmann. "A Geografia e o Resgate da Geopolítica”. Espaço Aberto 2.1 (2012): 117-150.

Bénat-Tachot, Louise. "La Corogne et Séville: les horizons de l'expansion maritime espagnole (14921550)". eSpania 22 (2015). DOI: https://doi. org/10.4000/e-spania.25043 (17/04/2019).

Bénat-Tachot, Louise y otros. Les processus d'americanisation.Volúmenes I y II. Paris: Le Manuscrit, 2012.

Besse, Jean-Michel. Les grandeurs de la Terre. Aspects du savoir géographique à la Renaissance. Lyon: ENS Éditions, 2003.

Brendecke, Arndt. Imperio e información. Funciones del saber en el dominio colonial español. Madrid / Frankfurt: Iberoamericana / Vervuert, 2016.

Burgh, James. La cité des Césars. Une utopie en Patagonie. Paris: Utz / Éditions UNESCO, 1996.

Cuesta Domingo, Mariano. Alonso de Santa Cruz y su obra cosmográfica. Tomo I. Madrid: Consejo Superior de Investigaciones Científicas / Instituto Gonzalo Fernández de Oviedo, 1983.

Eamon, William. Science and the Secrets of Nature: Books of Secrets in Medieval and Early Modern Culture. Princeton: Princeton University Press, 1994.

Estellé, Patricio y Ricardo Couyoudmdjian. "La ciudad de los Césares: origen y evolución de una leyenda". Historia 7 (1968): 283-309.

Fernández López, Francisco. “La Casa de la Contratación de Indias: gestión, expedición y control documental (siglos XVI-XVII)". Relaciones. Estudios de Historia y Sociedad 36.144 (2015): 169-193.

Freedman, Paul. Lo que vino de Oriente. Las especias y la imaginación medieval.Valencia: Universitat de València, 2010.

Fuentes Crispín, Nara. Periplos ilustrados, piratas y ladrones en el Caribe colonial. Bogotá: Universidad Nacional de Colombia, 2013.

García Redondo, José María. Cartografía e imperio. El Padrón Real y la representación del Nuevo Mundo. Madrid: Ediciones Doce Calles, 2018.

González Alonso, Nuria. "Diego Flores deValdés y la expedición al estrecho de Magallanes en el año 1581”. Anales del Museo de América 22 (2014): 152-161.

González-Barrera, Julián. "La derrota a través del Estrecho de Magallanes: el viaje olvidado de Juan Ladrillero (1557-1559)”. Atenea 501 (2010): 11-33.

Goodman, David C. Power and Penury. Government, technology and science in Philip II's Spain. Cambridge: Cambridge University Press, 2002.

Herrera Ángel, Marta. El conquistador conquistado. Awás, Cuayquer y Sindaguas en el Pacífico colombiano, siglos XVI-XVIII. Bogotá: Ediciones Uniandes, 2016.

Hiatt, Alfred. Terra Incognita. Mapping the Antipodes before 1600. Londres: British Library, 2008.

Ita Rubio, Lourdes de. Viajeros Isabelinos en Nueva España. Morelia / México: Universidad Michoacana de San Nicolás de Hidalgo / Fondo de Cultura Económica, 2001. 
Laboulais-Lesage, Isabelle. Dir. Combler les blancs de la carte. Modalités et enjeux de la construction des savoirs géographiques (XVIIe-XXe siècle). Estrasburgo: Presses Universitaires de Strasbourg, 2004.

Lestringant, Frank. L'atelier du cosmographe, ou l'image du monde à la Renaissance. Paris: Albin Michel, 1991.

Lois, Carla. "Quinta pars o terrae incognitae? La cuestión de la verosimilitud en la representación cartográfica de lo desconocido”. Terra Brasilis 4 (2015). DOI: https://doi.org/10.4000/terrabrasilis.1084 (14/05/2019).

. Terrae incognitae. Modos de pensar y mapear geografías desconocidas. Buenos Aires: Eudeba, 2018.

Long, Pamela O. Openness, Secrecy, Authorship. Technical Arts and the Culture of Knowledge from Antiquity to the Renaissance. Baltimore:The John Hopkins University Press, 2004.

Moreno Jeria, Rodrigo. "El estrecho de Magallanes como antesala del Pacífico: evolución cartográfica y toponimia entre los siglos XVI y comienzos del XVIII". Anuario de Estudios Americanos 70.2 (2013): 419-439.

Onetto Pavez, Mauricio. “Los 'descubrimientos' del estrecho de Magallanes. La relación de los ayudantes del piloto-cosmógrafo Juan Ladrillero, 15571558". Anales de Literatura Chilena (2020). [En prensa].

Parker, Geoffrey. Imprudent King: A New Life of Phillip II. New Haven:Yale University Press, 2014.

Pérez-Mallaína Bueno, Pablo Emilio. Naufragios en la Carrera de Indias durante los siglos XVI-XVII. El hombre frente al mar. Sevilla: Editorial Universidad de Sevilla, 2015.

Peters, Edward. "The Desire to Know the Secrets of the World". Journal of the History of Ideas 62.4 (2001): 593-610.

Pimentel, Juan. "Sighting and Haunting of the South Sea: On Ponquiaco, Balboa, and What Maps Conceal". Translating Nature. Cross-Cultural Histories of Early Modern Science. Eds. Jaime Marroquín Arredondo y Ralph Bauer. Philadelphia: University of Pennsylvania Press, 2019.

Portuondo, María M. Ciencia secreta. La cosmografía española y el Nuevo Mundo. Madrid / Frankfurt: Iberoamericana / Vervuert, 2013.

Russo, Alessandra. L'image intraduisible. Une histoire métisse des arts en Nouvelle-Espagne (1500-1600). Paris: Les Presses du Réel, 2013.

Sánchez Martínez, Antonio. La espada, la cruz y el Padrón. Soberanía, fe y representación cartográfica en el mundo ibérico bajo la Monarquía Hispánica, 1503-1598. Madrid: Consejo Superior de Investigaciones Científicas, 2013.

. "Los artífices del Plus Ultra: pilotos, cartógrafos y cosmógrafos en la Casa de la Contratación de Sevilla durante el siglo XVI". Hispania. Revista Española de Historia 70.236 (2010): 607-632.

Sempat Assadourian, Carlos. "La renta de la encomienda en la década de 1550: piedad cristiana y desconstrucción”. Revista de Indias 48.182-183 (1988): 109-146.

Solano Francisco de. Ed. Cuestionarios para la formación de las Relaciones Geográficas 
de Indias. Siglos XVI-XIX. Madrid: Consejo Superior de Investigaciones Científicas, 1988.

Urbina, María Ximena. "La expedición de John Narborough a Chile, 1670: defensa de Valdivia, rumores de indios, informaciones de los prisioneros y la creencia en la ciudad de los Césares”. Magallania 45.2 (2017): 11-36.

Vas Mingo, Milagros del. Las capitulaciones de Indias en el siglo XVI. Madrid: Instituto de Cooperación Iberoamericana, 1986.

Zuleta Carrandi, Joaquín. "La fortificación del estrecho de Magallanes: un proyecto al servicio de la imagen de la monarquía”. Revista Complutense de Historia de América 39 (2013): 153-176. 